\title{
A Mathematical Model Proposal for Establishing the Appropriate Urban Transformation
}

\author{
Halil İbrahim Polat* \\ Yildiz Technical University, Istanbul, Turkey
}

*Corresponding author: Halil İbrahim Polat, Yildiz Technical University, Istanbul, Turkey.

Received Date: April 01, 2019

Published Date: April 18, 2019

\begin{abstract}
In order to be able to find the appropriate urban transformation system, it is necessary to determine, collect and transfer to a database the structural and regional data belonging to a specific area. The mathematical model is thought to contribute directly to urban planning with a fair and easily accessible calculation method. In the course of planning a zone, it can be assumed that in order to be handled land-use in the most efficient way, the relationship between the parameters related to the land is important in terms of enabling the most appropriate planning to be made. In this respect, it is thought that the use of a calculation method or model can prepare the ground for a healthy and sustainable planning work while planning a region. For this reason, appropriate urban transformation model (AUTM) which is a system to shed light on planning, has been studied.
\end{abstract}

Keywords: Urban transformation; mathematical model; planning

\section{Introduction}

The first and most important factor determining earthquake behavior is land use. It is understood that urban planning and design factors play a serious role in decreasing earthquake damages as well as creating the formation of urban image. There is no question of making decisions about urban design that are independent of city planning criteria and urban development plans. Because plan decisions are an important guide in urban design. Unconsciously developed designs can also negatively affect local or regional earthquake behavior [1]. Transformation means to take another form, to change shape, to convert, to reform [2]. It also includes changes in physical, functional, social, economic, and ecologically worn-out in a particular area [3]. Urban transformation is also defined as a comprehensive vision and action that provides a solution to urban problems and a permanent solution to the economic, physical, social and environmental conditions of an area to be transformed [4]. In particular, after the 1980s, the accumulation, investment and change in forms of production and industrialization influence by globalization caused to undergo significant changes in terms of both social and special aspects of urban areas. Parallel to these changes, an interrogation process has started for planning. The change in the conceptual structure of planning has also brought about changes in its application areas and tools. Urban transformation, which has developed different approaches within the historical process of planning, is also one of the application tools utilized to reconstruct cities [5].

Urban transformation can be regarded as one of the most accurate methods of improving the living conditions of the area without changing the demographic structure of the existing population [6]. In this sense, the structural and regional data of the area to be transformed is of great importance. It is at the very beginning of these steps to prepare a research report for the area of transformation. Within the scope of the research report should be made within the headings of; current situation analyses, demographic and socio-economic structure of the region, structure analysis in geological and geotechnical context, earthquake risk, physical structure analysis (building functions, floor units, building types, building quality, density), property status, top scale planning and investment decisions, $1 / 5000$ scale master plan, 1/1000 scale implementation plan, transportation and technical infrastructure. All these headings have been placed under the AUTM. The research reports should be made in a comprehensive way and all data and parameters belonging to the region should be displayed on the basis of implementation of the most appropriate transformation decisions. In summary; research reports represent an important 
preparation period in the context of planning and forming a basis for transformation-oriented projecting studies by feasibility studies of the district, expectations of households, surveys that capture the current situation, working sheets, determination the matters of the current and future situation of the region.

\section{Materials and Methods}

The main characteristics of the areas for which model entry is to be performed; are the regions with high-density, illegal and urban sprawl settlements in the form of depression zones of highly developed metropolises such as Barcelona, Istanbul, Paris, Rome and Berlin. In addition; comparing to metropolitan, high-density neighborhoods and smaller settlements in terms of population are also included in the study of the model. The areas to be based on the model are not historical districts and does not include historical buildings a lot.

\section{Current residential land-use area data}

The purpose of this article is; to determine the appropriate planning criteria and to analyze the extent to which these criteria can be approached in recent years in urban transformation works based on mitigation of earthquake risks in Turkey, mainly in Istanbul (Figure 1).

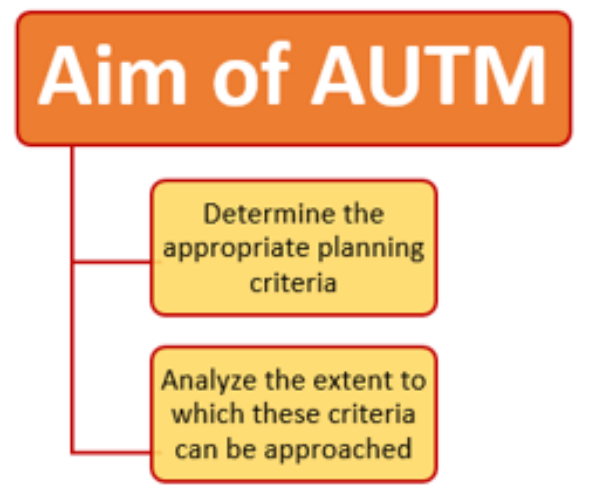

Figure 1: Aim of appropriate urban transformation model.

On a mathematical model proposal has been worked to find the appropriate urban transformation system in terms of the distribution of urban and social infrastructural areas, density, transportation data and gross and net construction sites within the framework of earthquake parameters, which will shed light on the urban transformation studies that are constantly updating in the world in the context of planning criteria. It is thought that this mathematical model will help to determine all the vital decisions that will be made on behalf of planning in the project area during the urban transformation process.

\section{Mathematical model and upper groups}

Mathematical model can be expressed in most general definition as a suitable design developed in order to bring high urban standards, healthy, sustainable and livable cities. This work is framed by a model that extends from urban and social infrastructure to cost, construction and seismicity. In this context, the relevant literature has been searched, the standards have been examined, the numerical values obtained have been entered into the database and the numerical infrastructure that constitute the skeleton of the targeted model has been created by analyzing the data. In this respect, a unique approach and model has been tried to reveal in the field of urban transformation by determining the criteria related to the appropriate urban transformation model (AUTM) by collecting, evaluating, benchmarking and filtering the universal data and parameters related to the urban transformation.

In the mathematical model, there are 4 model upper groups within the sub-headings of existing and appropriate situations. From these; A model upper group contains urban and social infrastructure data, B model upper group contains construction data, C model upper group contains cost data, and the D model upper group contains seismicity that taken part in an algorithmic relation. As seen in the macro interaction data flow chart in Figure 2 , data and analysis results of model A group are determinant factors in the calculation of B and $\mathrm{C}$ model upper group. B model upper group only affects $\mathrm{C}$ model upper group and D model upper group is transferring data to $\mathrm{B}$ model upper group. There is no data flow towards the A and D model upper groups from the other model upper groups. There is no transfer of data from the $\mathrm{C}$ model upper group to the other model upper groups. The B model upper group has both the data flow toward itself and the data transfer towards to the other model upper groups (Figure 2).

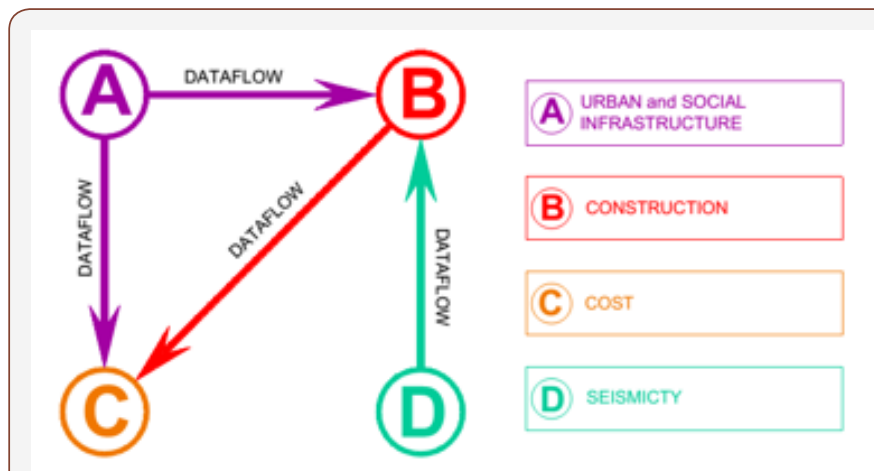

Figure 2: Macro interaction data flow diagram.

By determining the constant values (e.g., project area) and entering the foreseen values (e.g., intensity, urban infrastructure land-use areas, etc.) into the database, urban data are obtained on a regional basis for the likely place of transformation. Model integration is achieved by establishing the interaction diagram of all parameters. These parameters are divided into groups, some of which are obtained as percentage data within the urban area, and others are processed with units per person. The designed mathematical model has been tested in some depressed areas of large cities with high density in urban sprawl [7]. Thus, the effectiveness of the model, the workings of the algorithms, the outputs and the results are examined and evaluated. For the proper parameters; limit values determined based on the world standards and norms, practices and regulations are analyzed. 


\section{Model working method}

The working method of this model is firstly to determine the existing parameters of the field to be studied, to collect the data (feasibility) and to transfer it to a database. Afterwards, the data are analyzed with mathematical formulas developed and evaluations are made on transformation decisions. The results of analysis of all numerical data reveal a table which help interpret the question of whether transformation is necessary. The analysis is completed if it is deemed the transformation for the project area not required according to this numerical tabulation. Otherwise, the corresponding model operation for the area starts.

In order to reach the appropriate model, firstly the parameters determined in the current model and the new parameters and numerical inputs determined in the direction of the field need to be analyzed. In the calculations made in the appropriate model study, it is analyzed whether or not the mathematical model provides the appropriate urban transformation model in the framework of the integrated numerical criteria and the accepted limit values, with reference to the national and international planning criteria and by developing the suggestions. Accepted values for each data item labelled as "appropriate" are not final (indefinite) but actually indicate a range of values. If the selected numerical inputs are in the range of the integrated value of the appropriate model, the analysis is completed with the AUTM obtained. Otherwise; if one or more limit values are not met, the analysis continues by changing the digital inputs until the corresponding criteria are met and the appropriate model is obtained. In this way; an appropriate urban transformation model which can provide national and international standards to a large extent can be put forward. The advantage of the model is, having two separate calculation methods as Application-1 and Application-2 (Figure 3).

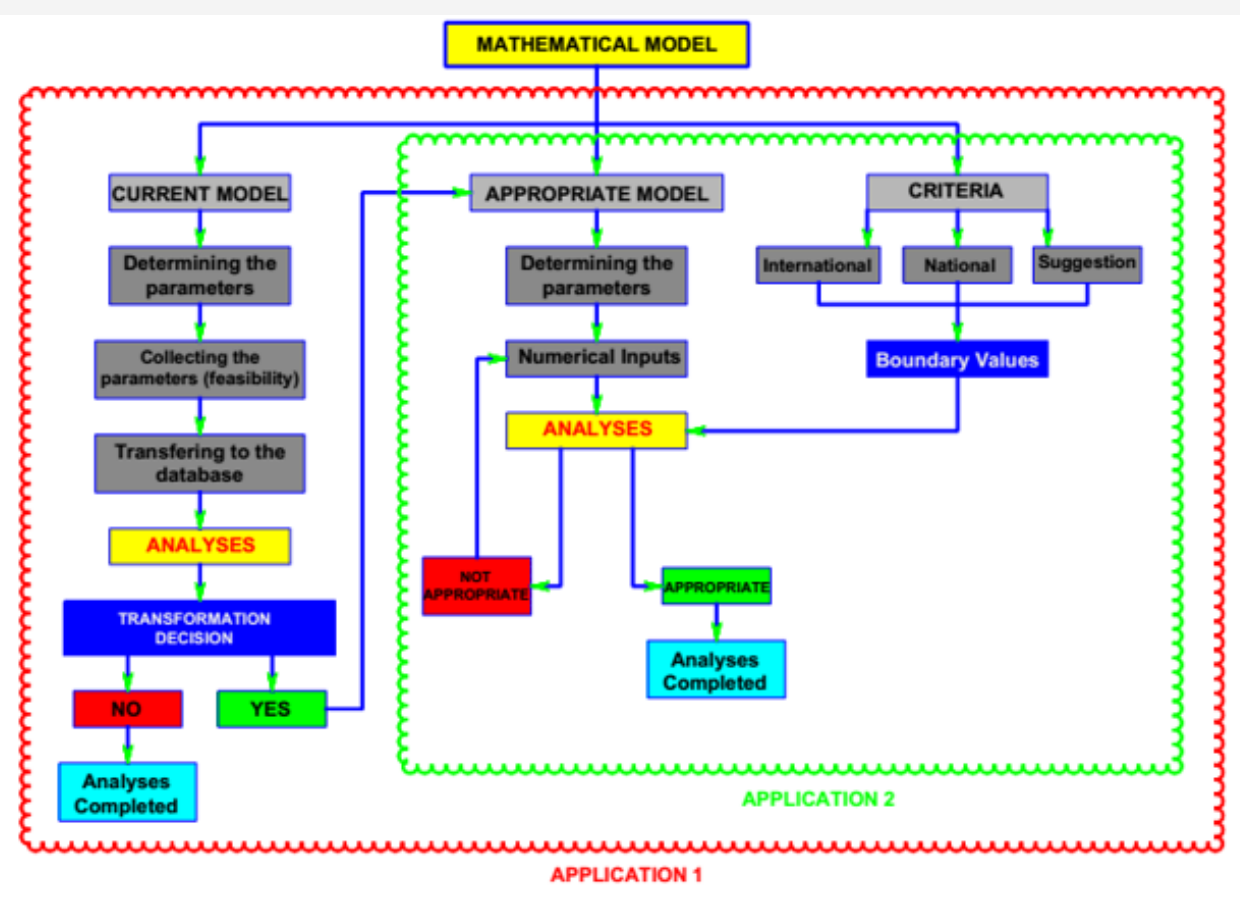

Figure 3: Mathematical model flowchart diagram.

According to Application-1, a model is obtained in which the closest results to the appropriate situation are achieved within the boundary values in the light of the information of all feasibility studies (Figure 4).

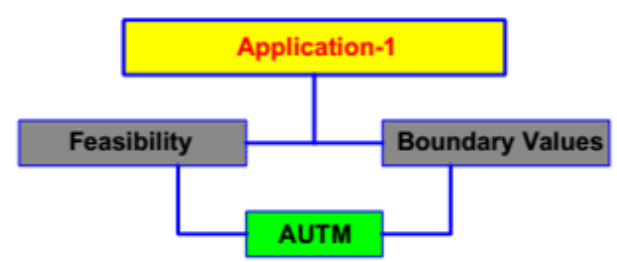

Figure 4: Application-1 working method.

Only with the project area parameter instead of feasibility studies, a predicted model is obtained with Application-2. This means that AUTM works with the project area data, but it could not be a certain model which helps to have a positive approach for transformation. Besides a model working with only a current parameter has an undeniable advantage. Application-2 tries to obtain a forecast during the studies and before making decisions about transformation (Figure 5).

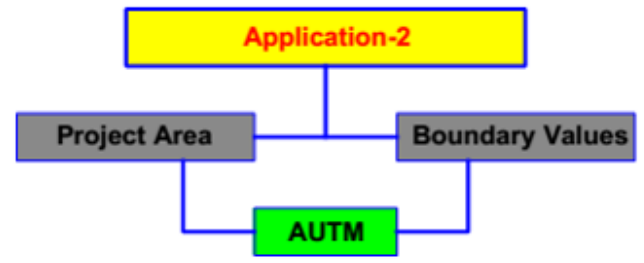

Figure 5: Application-2 working method. 
In all calculations belonging to the model; algorithmic computations and analyzes were made with MATLAB and SQL database background, and Microsoft Office Excel and Microsoft Office Access programs were used for the interface. The mathematical model for obtaining the appropriate urban transformation system will shed light on the vital decisions for the project area during the urban transformation process. This mathematical model can be integrated into the subject area when the feasibility studies of the area are made, or the research report is not written yet. Both application methods draw a picture with general lines of the project area by the mathematical model. In terms of planning and seismicity criteria, the distribution of urban and social infrastructure areas, density, gross and net construction areas, over ground and underground construction areas can be calculated. As long as planning standards and boundary conditions are not met, the changes of the numerical inputs are reflected in the model again to obtain new data, restart the process and target the closest situation to the appropriate model. In the model, boundary values are determined by developing suggestions from references to world standards and norms. If the parameters which are not within the limit value range between the reports and outputs, the model warns so, the subject parameters are interfered and can be taken within the boundary values by changing the values of the other input data.

\section{Appropriate Urban Transformation Model Data Interaction Schema}

In AUTM, there are some subgroups under 4 model upper groups. These subgroups shape the micro interaction scheme by transferring data to the other groups of the model (Figure 6).
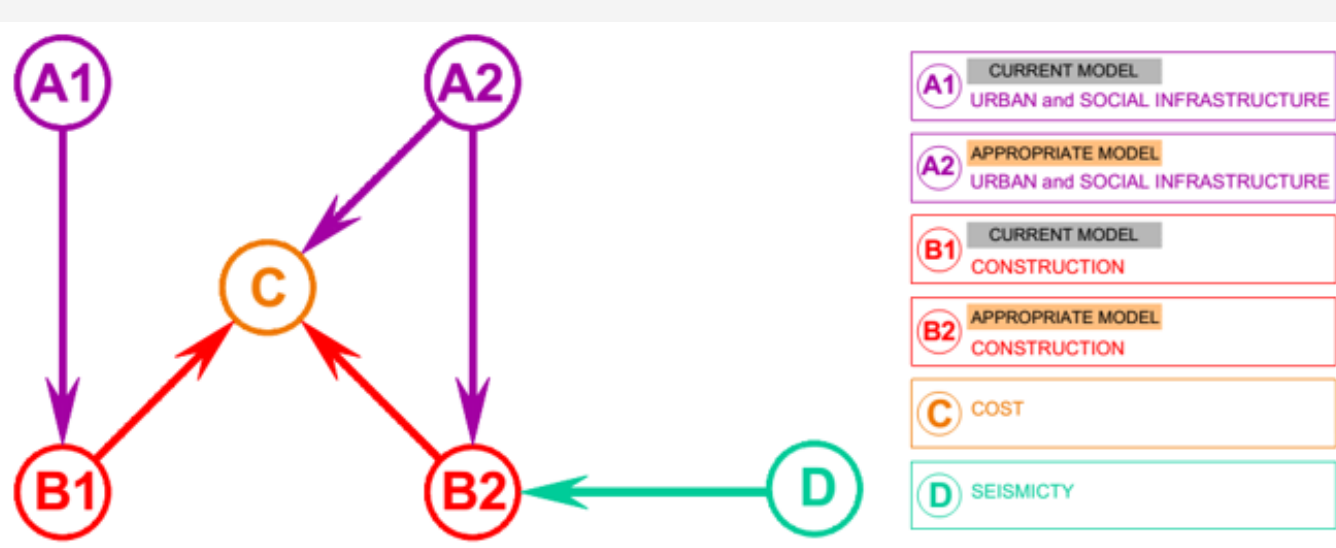

Figure 6: Micro interaction data flow diagram.

While the upper groups of A and B models are divided into two model subgroups, the $\mathrm{C}$ and $\mathrm{D}$ models perform the same function as their upper groups are engaged in exchanges. According to this the mathematical model subgroups and upper groups include:

1. A - Urban and social infrastructure (intensity, public improvements, transportation, etc.)

2. A1- Current model of urban and social infrastructure

3. A2- Appropriate model of urban and social infrastructure

4. B - Construction (FAR, footprint areas, gross and net construction areas, parking lot, etc.)

5. B1- Current model of construction

6. B2- Appropriate model of construction

7. C - Cost (construction, excavation, demolition etc. costs)

8. D - Seismicity (earthquake region, ground group, etc.).

According to the network of relationships in Figure 6 providing data transfer ways are from A1 - Current model of urban and social infrastructure to B1 - Current model of construction, from A2- Appropriate model of urban and social infrastructure to B2 -
Appropriate model of construction and to C - Cost model upper group. While B1 and B2 model subgroups provide data to $\mathrm{C}$ model upper group, D - Seismicity model upper group provides data to B2 model subgroup. The A1, A2 model subgroups and the D model upper groups do not have any data stream towards them. There is no data flow to the other model groups from the $\mathrm{C}$ upper group.

\section{Conclusion and Evaluation}

The concept of urban transformation is still an up-to-date issue which provides a method for renewal of areas that have been at a high-level risk of natural disaster and earthquake probability. These areas are generally, socially underdeveloped and overcrowded with high population density over its capacity. Urban transformation obtains a mission to provide the opportunity to make a new plan within the local and international criteria especially in the metropolitan suburbs where unpredicted population increases threatens the urban structure with unlicensed and illegal buildings. This concept has often been viewed as having a tendency of earthquake from the past to the present, and recently it has become widespread that basic arguments of transformation should be based on the parameters in planning. In this article, instead of working on individually reconstruction of the buildings as risky 
originating from earthquake, has been sought to develop an Appropriate Urban Transformation Model (AUTM) that allows for an area-oriented planning approach within the framework of national and international norms.

An algorithmic calculation and analysis study was carried out in which the interaction of the parameters with each other can be examined and replaced with a dynamic method in the obtained mathematical model which is called "Appropriate Urban Transformation Model (AUTM)" under the upper model groups of "urban and social infrastructure", "construction", "cost" and "seismicity" which contain density, population, urban open space, FAR, footprint areas, parking lots, over ground and underground construction areas, building height and floor quantity, etc. Thus, an urban transformation model based on the reduction of earthquake risks within the appropriate planning standards is emphasized. In other words, the closest planning criteria is determined for the appropriate model, and it was attempted to compare how close these criteria could be approached.

\section{Acknowledgement}

None.

\section{Conflict of Interest}

No conflict of interest.

\section{References}

1. Balyemez S, Berköz L (2005) Hasar Görebilirlik ve Kentsel Deprem Davranışı, Istanbul Technical University Journal /a, Mimarlık, Planlama, Tasarım 4(1): 3-4.

2. TDK (2016) Turkish Language Association, Kentsel dönüșüm.

3. Kılıç A (2006) Dönüşüm-Kentsel Yenileme Kavramları ve Yaklaşımlar, Ege Mimarlık Journal.

4. Thomas S (2003) A Glossary of Regeneration and Local Economic Development; Press: Manchester: Local Economic Strategy Center, UK, p.15

5. İnce E (2006) Kentsel Dönüşümde Yeni Politika, Yasa ve Eğilimlerin Değerlendirilmesi, Kuzey Ankara Giriși (Protokol Yolu) Kentsel Dönüșüm Projesi, Master Thesis, Gazi University, Ankara, Turkey.

6. Polat Hİ (2016) A Model Suggestion for Obtaining the Ideal Urban Transformation System in the Light of Density and Population Parameters and Kemalpasa Area Sample. International Journal of Advances Research and Review 1(10): 14-25.

7. Polat Hİ (2016) A Mathematical Model Suggestion for Land-Use Based on Urban Infrastructure. Asian Journal of Advanced Basic Sciences 5(1): $30-40$. 